\title{
SONICATION OF CHERRY JUICE: COMPARISON OF DIFFERENT SONICATION TIMES ON COLOR, ANTIOXIDANT ACTIVITY, TOTAL PHENOLIC AND ASCORBIC ACID CONTENT
}

\author{
G. YILDIZ ${ }^{\dagger}$ and H. FENG \\ $\dagger$ Igdir University, Faculty of Engineering, Food Engineering Department, Iğdır, Turkey \\ gulcn86@gmail.com (Corresponding author) \\ $\ddagger$ Department of Food Science and Human Nutrition, University of Illinois at Urbana-Champaign, Urbana, IL, USA
}

\begin{abstract}
C This study was conducted to investigate the effect of different ultrasound (US) times intervals on the physiological quality of cherry juice for a period of 14 days. Cherry fruits purchased from a local market were sonicated at $20 \mathrm{kHz}$ and $100 \%$ amplitude for $2,3,5$, and 10 minutes. Quality attributes such as color, total antioxidants, total phenolics and ascorbic acid contents of the cherry juices were compared. The results showed that the US treatment had significant effects on the physiological quality of the cherry juices. When the sonication treatment time was increased from 2 to 10 min, higher levels of total phenolic content, antioxidant activity, and ascorbic acid were observed. A 10 min treated cherry juices showed higher lightness $\left(L^{*}\right)$ values compared to the fresh cherry juice during a two-week period. Sonication treatment showed a potential as a method to preserve and improve the overall quality of cherry juice during cold storage.
\end{abstract}

Keywords - Ultrasound, cherry juice, color, ascorbic acid, total phenolic content.

\section{INTRODUCTION}

In the processing of fruit and vegetable juices, a thermal pasteurization method, normally a high temperature short time (HTST) treatment is often used in order to secure microbial safety of the food products. Even though HTST effectively inactivates human pathogens in the juice, it generally causes unwanted quality degradation such as nutrient, color, and sensory property changes in the juices (Ragsdale and Sisler, 1994). To overcome or minimize the food safety and quality problem, non-thermal technologies such as ultrasound (US), high pressure homogenization (HPH), and pulsed electric field (PEF) have been proposed as promising alternatives to thermal pasteurization so that the changes of flavor and nutritional value can be minimized during processing (Jiménez-Sánchez et al., 2017). Recently, US treatment has been reported to be an attractive means in food science and technology due to its promising effects in food processing and preservation (Yildiz et al., 2016; Lee et al., 2016; Yildiz et al., 2017; Yildiz and Izli, 2019a). The lethal effect of ultrasound when applied to a liquid medium is attributed to the physical and chemical events in the medium produced by acoustic cavitation. This includes the formation, growth, and violent collapse of small bubbles in liquid as a result of acoustic pressure fluctuation (Knorr et al., 2004). Ultrasound has been tested in order to inactivate human pathogens in juice products, such as apple cider (Lee et al., 2013). Sonication of apple cider at $57^{\circ} \mathrm{C}$ and $20^{\circ} \mathrm{C}$ achieved $5 \log$ reduction of $E$. coli $\mathrm{O} 157: \mathrm{H} 7$ in about 4.5 and $6 \mathrm{~min}$, respectively (D'Amico et al., 2006). Even though several works have been done on the application of ultrasound during food processing and preservation, little information is known about the effect of ultrasound treatment as a factor that affects quality in vegetables and fruit after harvest. Previously, some studies have been conducted on different fruit juices treated with ultrasound, in particular kasturi lime juice (Bhat et al., 2011), orange juice (Tiwari et al., 2008), strawberry juice (Tiwari et al., 2009), watermelon juice (Rawson et al., 2011), grapefruit juice (Aadil et al., 2015), peach juice (Yildiz, 2019), and guava juice in combination with carbonation (Cheng et al., 2007). To the best of our knowledge, the effects of different sonication times on cherry juice quality parameters have not been reported anywhere else. Therefore, the objective of this study was to explore the effects of different sonication times (2,3,5, and $10 \mathrm{~min})$ on color, antioxidant activity, total phenolic and ascorbic acid contents of cherry fruit juices during storage at $4^{\circ} \mathrm{C}$ for 14 days. Even though the main focus was to analyze the effect of the different sonication times on the nutrient quality, preliminary studies for the microbial growth were performed at different sonication time to examine whether this emerging process can be applied as alternative to HTST. It is the study to determine the effect of different sonication treatments to investigate quality parameters and bioactive compounds on the storage stability of cherry juice.

\section{METHODS}

\section{A. Processing of raw material and US treatment}

Fresh cherry fruits (Northwest cherries) were purchased from a local market in Springfield, IL, USA. They were sorted to eliminate damaged or unripe fruit, and selected for uniform size and color. Juices of cherries were freshly pressed with using a juice extractor (Bullet Express Multifunction Food Processor, Model: BE 110, Pacoima, CA, USA) after removing the seeds from the fruit. The juice was filtered by using filter paper (Tri Clover Compatible Filter, CA, U.S.A) to remove the pulp and 
foreign materials. US treatment was applied by using a VC-750 US homogenizer (Sonic \& Material, Inc., Newtown, CT) with the frequency of $20 \mathrm{kHz}$ at $100 \%$ amplitude. A total of $500 \mathrm{~mL}$ of freshly squeezed cherry juices were put into a beaker, and the acoustic energy was transferred to the sample by a probe $(12.5 \mathrm{~mm}$ diameter). The beaker was put in an ice bath at the time of sonication to control the temperature of the sample. For control samples, no treatment was applied.

Below is the explanation of the samples and treatments used in the study:

- Fresh stands for "No ultrasound treatment"

- US2 stands for "Ultrasound treated cherry juices for 2 min at $100 \%$ amplitude"

- US3 stands for "Ultrasound treated cherry juices for 3 min at $100 \%$ amplitude"

- US5 stands for "Ultrasound treated cherry juices for 5 min at $100 \%$ amplitude"

- US10 stands for "Ultrasound treated cherry juices for $10 \mathrm{~min}$ at $100 \%$ amplitude"

\section{B. Color measurement}

Colors of cherry juices were measured by Hunter colorimeter (Hunter Associates Laboratories, Reston, VA) depend on the $L^{*}, a^{*}$, and $b^{*}$ values. Cherry juices $(10 \mathrm{~mL})$ were put into to a plastic dish $(35 \mathrm{~mm}$, Corning tissue culture dish, NY, USA). The instrument blank measurements were made with the cuvette filled with DW against a reference white pressed plate. For each cherry juice, three color measurements were taken and the averaged $L^{*}, a^{*}$, and $b^{*}$ values were calculated.

\section{Ascorbic Acid}

Ascorbic acid content of cherry juice was determined using 2,6-dichloro-indophenol titration as outlined by Jones and Hughes (1983). $10 \mathrm{~mL}$ of cherry juices were added into $10 \mathrm{~mL}$ of $3 \%(\mathrm{v} / \mathrm{v})$ metaphosphoric acid. The concentrate was completed to a volume of $100 \mathrm{~mL}$ and centrifuged at room temperature $(3000 \mathrm{~g}, 15 \mathrm{~min})$. The supernatant $(10 \mathrm{~mL})$ was titrated against standard 2,6dichloro-indophenol, which previously standardized against standard ascorbic acid and the result was reported as mg $100 \mathrm{~mL}^{-1}$ fresh weight (FW).

\section{Antioxidant capacity}

1,1-diphenyl-2picryl hydrazyl radical (DPPH) was utilized to examine the antioxidant capacity of fresh and US-treated cherry juices (Ebrahimzadeh et al., 2009). The cherry juice concentrates were made in several concentrations with the rates of $0.02 \%, 0.04 \%, 0.06 \%$, $0.08 \%$, and $0.1 \%$. DPPH compound was mixed with the sample concentrate, and then vortexed. The mixture was incubated in the dark for an hour. The solution was stirred and then centrifuged (3000 g, $10 \mathrm{~min}$ ). Finally, the absorbance was read of absorbance at $517 \mathrm{~nm}$ with a spectrophotometer (Lambda 1050 UV/VIS/NIR Spectrometer, PerkinElmer, Waltham, MA, U.S.A), and $\mu \mathrm{mol}$ of Trolox equivalents per liter $(\mu \mathrm{mol} \mathrm{TE} / \mathrm{L})$ of cherry juice was collected.

\section{E. Total phenolic content (TPC)}

TPC of fresh and US-treated cherry juices were determined using a modified colorimetric method (Igual et al., 2012). The technique includes the degradation of Folin-Ciocalteau indicator (Sigma Chemical, St. Louis, Missouri, U.S.A) by phenolic ingredients, with the formation of a blue compound. In shortly, the juice extract $(0.25 \mathrm{~mL})$ was added into $15 \mathrm{~mL}$ of distilled water and $1.25 \mathrm{~mL}$ of Folin-Ciocalteau testing agent. Following the $8 \mathrm{~min}$ waiting, $3.75 \mathrm{~mL}$ of saturated sodium carbonate was put added into the mixture and diluted up to $25 \mathrm{~mL}$ with DW. Then, the blend was kept at $25{ }^{\circ} \mathrm{C}$ for an hour and the absorbance was read at $765 \mathrm{~nm}$ by a spectrophotometer (Lambda 1050 UV/VIS/NIR Spectrometer, PerkinElmer, Waltham, MA, USA). Gallic acid was used as a reference standard, and the results were described as $\mathrm{mg}$ gallic acid equivalents per liter of juice (mg GAE/L).

\section{F. Shelf life}

After US treatments, the juice samples were stored at $4^{\circ} \mathrm{C}$ for two-weeks, and analyses were conducted at 0,2 , 5,7 , and 14 days of storage.

\section{G. Statistical analysis}

Three replications for each treatment were used for all measurements. Statistical analyses were conducted using the General Linear Models procedure in SAS (version 9.3, SAS Institute, Inc., Cary, North Carolina, USA). Fisher's least significant difference (LSD) test was conducted to figure out statistical changes among treatments at alpha $=0.05$.

\section{RESULTS AND CONCLUSIONS}

\section{A. Color measurement}

Table 1 shows the changes in $L^{*}, a^{*}$, and $b^{*}$ values for cherry juices treated with ultrasound during a two-week period. The $L^{*}$ (lightness) values of all treated cherry juices were slightly higher than the fresh processed samples right after processing. For other storage times, all US-treated cherry juices no matter which treatment showed significantly higher $L^{*}$ values compared to the fresh cherry juice (Table 1 ). The increase in $L^{*}$ values for sonicated juice samples as compared control was also observed in the study of sonicated watermelon juice (Rawson et al., 2011). The $L^{*}$ values decreased significantly with the storage time in cherry juices for all treatments, but especially in fresh cherry juice. The highest $L^{*}$ value was observed for the samples on day 0 , and the lowest $L^{*}$ value was observed for the last day $\left(14^{\text {th }}\right.$ days) juice samples. No significant changes were observed between cheery juices treated with and without ultrasound in their $a^{*}$ (redness) and $b^{*}$ (yellowness) values during 2 weeks of storage (Table 1 ). In addition, the sonicated cherry juice samples showed slightly lower $a^{*}$ and $b^{*}$ values in comparison with fresh juice which is in agreement with the work of Tiwari et al. (2008) for sonicated orange juice. It has been reported that cavitation phenomena occurred during ultrasound might cause changes on the color of fruit juices (Cheng 
Table 1. Change of color in fresh and sonicated cherry juices over storage at $4{ }^{\circ} \mathrm{C}$

\begin{tabular}{|c|c|c|c|c|}
\hline Treatments & Storage (days) & $\boldsymbol{L}^{\mathrm{u}}$ & $\boldsymbol{a}^{\mathrm{a}}$ & $\boldsymbol{b}^{\mathrm{a}}$ \\
\hline & 0 & $74.1 \pm 0.98^{\mathrm{a}}$ & $11.8 \pm 0.12^{\mathrm{a}}$ & $1.5 \pm 0.02^{\mathrm{a}}$ \\
& 2 & $71.5 \pm 0.86^{\mathrm{b}}$ & $11.2 \pm 0.15^{\mathrm{a}}$ & $1.3 \pm 0.01^{\mathrm{a}}$ \\
FRESH & 5 & $68.2 \pm 0.88^{\mathrm{c}}$ & $11.8 \pm 0.23^{\mathrm{a}}$ & $1.2 \pm 0.04^{\mathrm{a}}$ \\
& 7 & $62.9 \pm 0.65^{\mathrm{d}}$ & $11.5 \pm 0.22^{\mathrm{a}}$ & $1.4 \pm 0.07^{\mathrm{a}}$ \\
& 14 & $55.2 \pm 0.48^{\mathrm{e}}$ & $11.2 \pm 0.34^{\mathrm{a}}$ & $1.3 \pm 0.03^{\mathrm{a}}$ \\
\hline \multirow{4}{*}{ US2 } & 0 & $74.2 \pm 0.43^{\mathrm{a}}$ & $11.0 \pm 0.55^{\mathrm{a}}$ & $1.3 \pm 0.02^{\mathrm{a}}$ \\
& 2 & $74.1 \pm 0.12^{\mathrm{a}}$ & $11.2 \pm 0.43^{\mathrm{a}}$ & $1.2 \pm 0.04^{\mathrm{a}}$ \\
& 5 & $70.8 \pm 0.18^{\mathrm{b}}$ & $11.3 \pm 0.46^{\mathrm{a}}$ & $1.1 \pm 0.06^{\mathrm{a}}$ \\
& 7 & $68.1 \pm 0.22^{\mathrm{c}}$ & $11.5 \pm 0.38^{\mathrm{a}}$ & $1.4 \pm 0.03^{\mathrm{a}}$ \\
& 14 & $62.9 \pm 0.35^{\mathrm{d}}$ & $11.7 \pm 0.33^{\mathrm{a}}$ & $1.4 \pm 0.07^{\mathrm{a}}$ \\
\hline \multirow{4}{*}{ US3 } & 0 & $74.4 \pm 0.73^{\mathrm{a}}$ & $11.2 \pm 0.44^{\mathrm{a}}$ & $1.5 \pm 0.04^{\mathrm{a}}$ \\
& 2 & $74.0 \pm 0.84^{\mathrm{a}}$ & $11.4 \pm 0.48^{\mathrm{a}}$ & $1.3 \pm 0.02^{\mathrm{a}}$ \\
& 5 & $71.8 \pm 0.95^{\mathrm{b}}$ & $11.6 \pm 0.56^{\mathrm{a}}$ & $1.3 \pm 0.01^{\mathrm{a}}$ \\
& 7 & $68.3 \pm 0.81^{\mathrm{c}}$ & $11.5 \pm 0.61^{\mathrm{a}}$ & $1.4 \pm 0.02^{\mathrm{a}}$ \\
& 14 & $63.8 \pm 0.66^{\mathrm{d}}$ & $11.8 \pm 0.32^{\mathrm{a}}$ & $1.6 \pm 0.03^{\mathrm{a}}$ \\
\hline \multirow{3}{*}{ US5 } & 0 & $74.6 \pm 0.63^{\mathrm{a}}$ & $11.2 \pm 0.23^{\mathrm{a}}$ & $1.2 \pm 0.03^{\mathrm{a}}$ \\
& 2 & $74.2 \pm 0.56^{\mathrm{a}}$ & $11.0 \pm 0.43^{\mathrm{a}}$ & $1.7 \pm 0.02^{\mathrm{a}}$ \\
& 5 & $70.9 \pm 0.76^{\mathrm{b}}$ & $11.2 \pm 0.32^{\mathrm{a}}$ & $1.6 \pm 0.05^{\mathrm{a}}$ \\
& 7 & $68.4 \pm 0.12^{\mathrm{c}}$ & $11.6 \pm 0.13^{\mathrm{a}}$ & $1.6 \pm 0.08^{\mathrm{a}}$ \\
& 14 & $68.1 \pm 0.23^{\mathrm{c}}$ & $11.6 \pm 0.24^{\mathrm{a}}$ & $1.1 \pm 0.09^{\mathrm{a}}$ \\
\hline \multirow{6}{*}{ US10 } & 0 & $74.8 \pm 0.76^{\mathrm{a}}$ & $11.3 \pm 0.43^{\mathrm{a}}$ & $1.5 \pm 0.09^{\mathrm{a}}$ \\
& 2 & $74.2 \pm 0.99^{\mathrm{a}}$ & $11.2 \pm 0.48^{\mathrm{a}}$ & $1.4 \pm 0.05^{\mathrm{a}}$ \\
& 5 & $71.7 \pm 0.65^{\mathrm{b}}$ & $11.8 \pm 0.54^{\mathrm{a}}$ & $1.4 \pm 0.04^{\mathrm{a}}$ \\
& 7 & $68.7 \pm 0.54^{\mathrm{c}}$ & $11.2 \pm 0.55$ & $1.7 \pm 0.07^{\mathrm{a}}$ \\
& 14 & $68.7 \pm 0.48^{\mathrm{c}}$ & $11.5 \pm 0.17^{\mathrm{a}}$ & $1.3 \pm 0.08^{\mathrm{a}}$ \\
\hline
\end{tabular}

${ }^{a-e}$ Treatment means within treatments with the same letter in each sample are not significantly different $(\mathrm{p}<0.05)$.

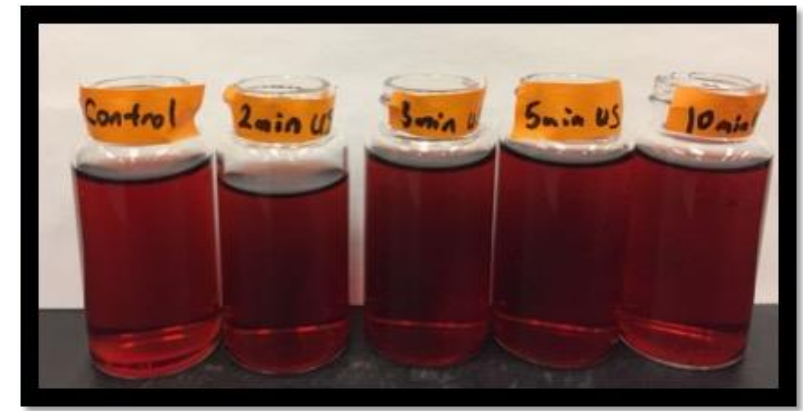

Fig. 1. The appearance of fresh and sonicated cherry juice samples.

et al., 2007; Tiwari et al., 2008). The observed color changes in this study might be from the physical effect of cavitation such as vibration, shock wave, localized high shear (Sala et al., 1995; Lee et al., 2013). The appearance of fresh and US-treated cherry juices is shown in Fig. 1. The color of US10 juice samples showed a closer look with the fresh juice by having a lighter appearance, while the other sonicated juices look darker.

\section{B. Ascorbic Acid Content}

Ascorbic acid changes of fresh and sonicated cherry juice samples are shown in Table 2. US5 and US10 juice samples showed significantly higher ascorbic acid content compared to the fresh cherry juice for all storage times. Especially when 10 min ultrasound was applied, the highest ascorbic acid content was achieved (Table 2). While the ascorbic acid content of fresh cherry juices was in the range of 35.35 to $61.73 \mathrm{mg} / 100 \mathrm{~mL}$, it was 46.60 to $61.97 \mathrm{mg} / 100 \mathrm{~mL}$ for the cherry juice treated with US for 10 minutes. In addition, fresh and US-treated cherry juices showed significant decrease in their ascorbic acid content during 2 weeks of storage. While the highest ascorbic acid content was determined on Day 0 , the lowest ascorbic acid was determined on Day 14. There are also several studies shows the increase in ascorbic acid content of sonicated fruit juices such as apple, guava and kasturi lime juices (Abid et al., 2014; Cheng et al., 2007; Bhat et al., 2011). The increase of ascorbic acid of cherry juice might attributed to the cavitation during sonication which is responsible for a removal the dissolved oxygen which is an essential for ascorbic acid degradation. Therefore, US-treated cherry juices might cause the higher ascorbic acid content by removing dissolved oxygen.

\section{Antioxidant activity}

Antioxidant capacity changes of fresh and US-treated cherry juices are presented in Table 2 . The antioxidant capacity values of fresh cherry juices were in the range 
of 897 to $1224 \mu \mathrm{mol}$ TE/L for 2 weeks. The antioxidant values of the US10 juices were in the range of 2027 to $3657 \mu \mathrm{mol}$ TE/L during 2 weeks. The antioxidant capacity increased significantly with the storage time in cherry juice samples for all methods (Fresh, US2, US3, US5, and US10) (Table 2). The lowest antioxidant value was observed for the samples on day 0 , and the highest antioxidant value was observed for the samples on day 14. Among the treatments, it was recorded that US10 juices showed the highest antioxidant capacity during the storage. A significant increase in total antioxidant capacity of sonicated juice samples was also observed in the study of Bhat et al. (2011). In our experiment, the antioxidant capacity increased significantly with the storage time in cherry juice samples for all methods. This increase might be attributed to the increased amount of phenolic compound as a result of cavitation produced during sonication. In several studies it was shown that there is a positive relationship between total phenolic content and antioxidant activity in many plant species such as kumquat and pomelo (Izli et al., 2018; Yildiz and Izli, 2019b) which is in an agreement with our findings. We have also observed a linkage between TPC and antioxidant activity. US10 treatment showed the highest TPC and antioxidant activity, while the fresh juices showed lowest antioxidant activity and TPC (Table 2).

\section{Total phenolic content (TPC)}

Total phenolic changes of fresh and US-treated cherry juice samples are demonstrated in Table 2. The phenolic content value of fresh cherry juices was changed from 165 to $326 \mathrm{mg}$ GAE/L for 2 weeks. On the other hand, TPC of US10 juice samples were found in the range of 427 to $697 \mathrm{mg} \mathrm{GAE} / \mathrm{L}$ for 3 weeks. The phenolic content values increased with the storage time in fresh and US-treated cherry juices. The highest phenolic content value was observed for all treatments on day 14, and the lowest phenolic content value was observed right after processing (Day 0). Phenolic compounds are very important and beneficial to human health as they play a significant role in controlling the risk of many physiological and degenerative diseases in the human body. It was found that that there was a significant increase in total phenols in all the sonicated juice samples as compared to control. Previous study conducted on sonicated kasturi lime juice also showed similar trend of increase

Table 2. Changes of ascorbic acid, antioxidant activity, and total phenolic content in fresh and sonicated cherry juices over storage at $4^{\circ} \mathrm{C}$.

\begin{tabular}{|c|c|c|c|c|}
\hline Treatments & Storage (days) & $\begin{array}{c}\text { Ascorbic Acid (mg/100 } \\
\text { mL) }\end{array}$ & $\begin{array}{c}\text { Antioxidant Activity } \\
(\mu \mathrm{mol} T \mathrm{TE} / \mathrm{L})\end{array}$ & $\begin{array}{c}\text { Total phenolic cont } \\
\text { (mg GAE/L) }\end{array}$ \\
\hline \multirow{5}{*}{ FRESH } & 0 & $61.73 \pm 1.18^{\mathrm{a}}$ & $897.14 \pm 104^{1}$ & $165 \pm 32^{\mathrm{f}}$ \\
\hline & 2 & $55.65 \pm 2.22^{\mathrm{b}}$ & $925.35 \pm 199^{\mathrm{i}}$ & $248 \pm 23^{e}$ \\
\hline & 5 & $44.21 \pm 1.34^{\mathrm{c}}$ & $998.22 \pm 123^{\mathrm{i}}$ & $269 \pm 18^{\mathrm{e}}$ \\
\hline & 7 & $40.33 \pm 1.89^{\mathrm{d}}$ & $1221.10 \pm 177^{\mathrm{h}}$ & $275 \pm 33^{\mathrm{e}}$ \\
\hline & 14 & $35.35 \pm 0.99^{\mathrm{e}}$ & $1224.23 \pm 189^{\mathrm{h}}$ & $326 \pm 42^{d}$ \\
\hline \multirow{5}{*}{ US2 } & 0 & $61.85 \pm 1.23^{\mathrm{a}}$ & $923.48 \pm 114^{1}$ & $234 \pm 24^{e}$ \\
\hline & 2 & $55.48 \pm 1.45^{\mathrm{b}}$ & $1423.13 \pm 156^{g}$ & $276 \pm 33^{\mathrm{e}}$ \\
\hline & 5 & $46.58 \pm 2.05^{\mathrm{c}}$ & $1943.53 \pm 122^{\mathrm{f}}$ & $327 \pm 65^{\mathrm{d}}$ \\
\hline & 7 & $41.44 \pm 2.18^{\mathrm{d}}$ & $2124.15 \pm 175^{\mathrm{e}}$ & $332 \pm 88^{d}$ \\
\hline & 14 & $35.37 \pm 2.16^{\mathrm{e}}$ & $2125.86 \pm 139^{\mathrm{e}}$ & $437 \pm 73^{\mathrm{c}}$ \\
\hline \multirow{5}{*}{ US3 } & 0 & $61.89 \pm 1.22^{\mathrm{a}}$ & $1224.35 \pm 148^{\mathrm{h}}$ & $323 \pm 76^{d}$ \\
\hline & 2 & $54.21 \pm 1.35^{\mathrm{b}}$ & $1514.36 \pm 198^{g}$ & $325 \pm 72^{d}$ \\
\hline & 5 & $46.25 \pm 1.98^{c}$ & $1525.12 \pm 192^{\mathrm{g}}$ & $338 \pm 65^{\mathrm{d}}$ \\
\hline & 7 & $40.86 \pm 2.09^{\mathrm{d}}$ & $2126.16 \pm 164^{\mathrm{e}}$ & $434 \pm 58^{c}$ \\
\hline & 14 & $36.20 \pm 1.78^{\mathrm{e}}$ & $2480.45 \pm 166^{\mathrm{d}}$ & $435 \pm 43^{c}$ \\
\hline \multirow{5}{*}{ US5 } & 0 & $61.75 \pm 1.13^{\mathrm{a}}$ & $1456.15 \pm 123^{g}$ & $325 \pm 44^{d}$ \\
\hline & 2 & $59.43 \pm 1.86^{\mathrm{a}}$ & $1984.48 \pm 145^{\mathrm{f}}$ & $328 \pm 12^{\mathrm{d}}$ \\
\hline & 5 & $59.20 \pm 1.23^{\mathrm{a}}$ & $2325.55 \pm 188^{\mathrm{d}}$ & $437 \pm 28^{c}$ \\
\hline & 7 & $55.64 \pm 1.87^{\mathrm{b}}$ & $2475.24 \pm 167^{\mathrm{d}}$ & $444 \pm 41^{c}$ \\
\hline & 14 & $46.24 \pm 1.65^{\mathrm{c}}$ & $2927.19 \pm 164^{c}$ & $545 \pm 25^{\mathrm{b}}$ \\
\hline \multirow{5}{*}{ US10 } & 0 & $61.97 \pm 2.05^{\mathrm{a}}$ & $2027.72 \pm 173^{\mathrm{e}}$ & $427 \pm 55^{\mathrm{c}}$ \\
\hline & 2 & $59.39 \pm 1.76^{\mathrm{a}}$ & $2418.65 \pm 144^{d}$ & $528 \pm 53^{b}$ \\
\hline & 5 & $59.18 \pm 1.22^{\mathrm{a}}$ & $2913.77 \pm 182^{c}$ & $597 \pm 89^{b}$ \\
\hline & 7 & $55.42 \pm 1.38^{\mathrm{b}}$ & $3180.23 \pm 131^{\mathrm{b}}$ & $646 \pm 73^{a}$ \\
\hline & 14 & $46.60 \pm 1.55^{\mathrm{c}}$ & $3657.18 \pm 144^{\mathrm{a}}$ & $697 \pm 77^{\mathrm{a}}$ \\
\hline
\end{tabular}

${ }^{a-i}$ Treatment means within treatments with the same letter in each sample are not significantly different $(\mathrm{p}<0.05)$. 
in total phenolic content (Bhat et al., 2011). This increase might be attributed to the release of bound form of phenolic contents due to breakage of cell wall by the cavitation pressure exerted on it during sonication.

The results demonstrated that the US treatment had significant effects on the physiological quality of the cherry juices. Cheery juice treated with US exhibited to be a promising alternative to HTST treatment as demonstrated by its quality retention ability during cold storage. When the sonication time was increased from 2 to 10 min higher levels of TPC, antioxidant capacity, and ascorbic acid were observed. A 10 min treated cherry juices showed higher lightness $\left(L^{*}\right)$ values compared to the untreated cherry juice during a two-week period. In overall, application of $10 \mathrm{~min}$ sonication at $20 \mathrm{kHz}$ maintains overall quality better than other US treatments. Based on the present study, we suggest that 10 min sonication may be implemented on a commercial scale for the production of cherry juice with improved quality and stability during storage to get more benefits.

\section{REFERENCES}

Aadil, R.M., Zeng, X.A., Zhang, Z.H., Wang, M.S., Han, Z., Jing, H. and Jabbar, S. (2015). "Thermosonication: A potential technique that influences the quality of grapefruit juice," Int. J. Food Sci. Technol., 50, 1275-1282.

Abid, M., Jabbar, S., Hu, B., Hashim, M.M., Wu, T., Lei, S. and Zeng, X. (2014). "Thermosonication as a potential quality enhancement technique of apple juice," Ultrason. Sonochem., 21, 984-990.

Bhat, R., Kamaruddin, N.S., Min-Tze, L. and Karim, A.A. (2011). "Sonication improves kasturi lime (Citrus microcarpa) juice quality," Ultrason. Sonochem., 18, 1295-1300.

Cheng, L.H., Soh, C.Y., Liew, S.C. and Teh, F.F. (2007). "Effects of sonication and carbonation on guava juice quality," Food Chem., 104, 1396-1401.

D’Amico, D.J., Silk, T.M., Wu, J. and Guo, M. (2006). "Inactivation of microorganisms in milk and apple cider treated with ultrasound," J. Food Prot., 69, 556-563.

Ebrahimzadeh, M.A., Nabavi, S.M., Nabavi, S.F. and Eslami, B. (2009). "Antioxidant activity of aqueous extract of Pyrus boissieriana fruit," Pharmacol., 1, 1318-1323.

Igual, M., García-Martínez, E., Martín-Esparza, M. and Martínez-Navarrete, N. (2012). "Effect of processing on the drying kinetics and the functional value of dried apricot," Food Res. Int., 47, 284290.

Izli, G., Izli, N., Taskin, O. and Yildiz, G. (2018). "Convective drying of kumquat slices: Comparison of different drying temperatures on drying kinetics, colour, total phenolic content and antioxidant capacity," Lat. Am. Appl. Res., 48, 37-42.

Jiménez-Sánchez, C., Lozano-Sánchez, J.A., SeguraCarretero, A. and Fernández-Gutiérrez, A. (2017).
"Alternatives to conventional thermal treatments in fruit-juice processing. Part 1: techniques and applications," Crit. Rev. Food Sci. Nutr., 57, 501-523.

Jones, E. and Hughes, R.E. (1983). "Foliar ascorbic acid in some angiosperms," Phytochem., 22, 2493-2499.

Knorr, D., Zenker, M., Heinz, V. and Lee, D.U. (2004). "Applications and potential of ultrasonics in food processing," Trends Food Sci. Technol., 15, 261266.

Lee, H., Kim, H., Cadwallader, K.R., Feng, H. and Martin, S.E. (2013). "Sonication in combination with heat and low pressure as an alternative pasteurization treatment - Effect on Escherichia coli K12 inactivation and quality of apple cider," Ultrason. Sonochem., 20, 1131-1138.

Lee, H., Yildiz, G., Dos Santos, L.C., Jiang, S., Andrade, J., Engeseth, N.C. and Feng, H. (2016). "Soy protein nano-aggregates with improved functional properties prepared by sequential $\mathrm{pH}$ treatment and ultrasonication," Food Hydrocoll., 55, 200-209.

Ragsdale, N.N. and Sisler, H.D. (1994). "Social and political implications of managing plant diseases with decreased availability of fungicides in the United States," Annu. Rev. Phytopathol., 32, 545557.

Rawson, A., Patras, A., Tiwari, B.K., Noci, F., Koutchma, T. and Brunton, N. (2011). "Effect of thermal and non-thermal processing technologies on the bioactive content of exotic fruits and their products: review of recent advances," Food Res. Int., 44, 1875-1887.

Sala, F.J., Burgos, J., Condon, S., Lopez, P. and Raso, J. (1995). "Effect of heat and ultrasounds on microorganisms and enzymes," In G.W. Gould (Ed.), New Methods of Food Preservation, 176-204.

Tiwari, B.K., Muthukumarappan, K., O'Donnell, C.P. and Cullen, P.J. (2008). "Colour degradation and quality parameters of sonicated orange juice using response surfacemethodology," LWT - Food Sci. Technol., 41, 1876-1883.

Tiwari, B.K., O’ Donnell, C.P., Muthukumarappan, K. and Cullen, P.J. (2009). "Effect of sonication on orange juice quality parameters during storage," Int. J. Food Sci. Technol., 44, 586-595.

Yildiz, G., Rababah, T. and Feng, H. (2016). "Ultrasound-Assisted Cutting of Cheddar, Mozzarella and Swiss Cheeses - Effects on Quality Attributes during Storage," Innov. Food Sci. Emerg. Technol., 37, $1-9$.

Yildiz, G., Andrade, J., Engeseth, N.E. and Feng, H. (2017). "Functionalizing soy protein nanoaggregates with $\mathrm{pH}$ shifting and mano-thermosonication," J. Colloid Interface Sci., 505, 836-846.

Yildiz, G. (2019). "Application of ultrasound and high pressure homogenization against high temperatureshort time in peach juice," J. Food Process Eng., 42, e12997.

Yildiz, G. and Izli, G. (2019a). "The effect of ultrasound 
pretreatment on quality attributes of freeze-dried quince slices: Physical properties and bioactive compounds," J. Food Process Eng., 42, e13223.

Yildiz, G. and Izli, G. (2019b). "Influence of microwave and microwave-convective drying on the drying kinetics and quality characteristics of pomelo," $J$. Food Process. Pres., 43, e13812.
Received October 30, 2018

Sent to Subject Editor: May 10, 2019

Accepted: September 16, 2019

Recommended by Subject Editor M. Luján Ferreira 